\title{
Measuring environmental policy stringency: approaches, validity, and impact on environmental innovation and energy efficiency
}

\author{
Marzio Galeottia,b,c, ${ }^{*}$, Silvia Salinid, and Elena Verdolini f,g

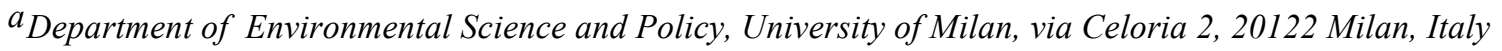 \\ ${ }^{b}$ Centro Studi Luca d'Agliano, Via Conservatorio 7, 20122 Milan, Italy \\ ${ }^{c}$ GREEN, Bocconi University, via Roentgen 1, 20136 Milan, Italy

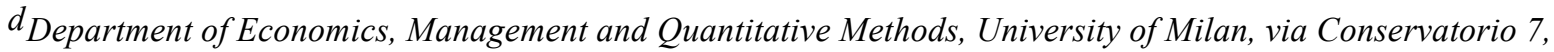 \\ 20122 Milan, Italy

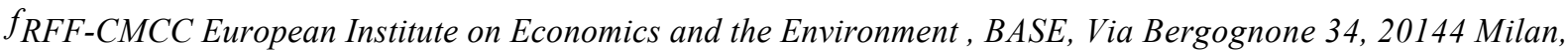

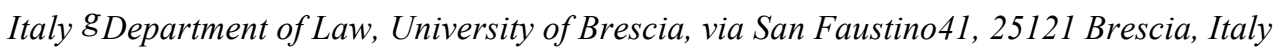

\begin{abstract}
Solid tests of the impact of environmental and energy policy on important economic outcomes, such as innovation, productivity, competitiveness and energy and carbon efficiency are impaired by the lack of appropriate empirical proxies for the commitment to, and stringency of, environmental policy. We contribute to the literature by: (1) computing different indicators of environmental policy stringency, (2) testing to what extent they convey similar insights through a statistical comparison exercise, and (3) showing the implications of using one or the other indicator in two illustrative empirical applications focused on environmental innovation and energy efficiency. We conclude by highlighting the implications of our analysis for empirical research focusing on the evaluation of policy impacts, and highlight fruitful future research avenues.
\end{abstract}

JEL classifications: Q58, O57, C33

Keywords: Energy policy, Environmental policy, Ranking, Environmental innovation, Energy-GDP relationship

* Corresponding author at: Department of Environmental Science and Policy, University of Milan, via Celoria 2, 20122 Milan, Italy

E-mail address: marzio.galeotti@unimi.it (Marzio Galeotti) 


\section{Introduction}

Raising concerns about the impact of anthropogenic greenhouse gas emissions (GHG) have recently pushed more and more governments to take concrete mitigation actions. To this end, countries are implementing increasingly stringent environmental policies which are aimed at internalizing the social cost of pollution or, alternatively, at reducing the price wedge between clean and dirty technologies. The implementation of more stringent environmental policies is accompanied by a lively debate on their impact on several key economic outcomes, such as productivity, competitiveness, and innovation.

On the one hand, many among researchers and policy makers hold that "you cannot have the cake and eat it, too", maintaining that environmental policy represents an additional cost (burden) for firms and consumers and that increased environmental quality will come at the expense of productivity and competitiveness, especially in light of the recent economic downturn. For instance, the so-called Pollution Haven Hypothesis postulates that increasing environmental standards will push polluting firms to relocate abroad, suggesting that this will likely harm the competitiveness and the welfare of citizens in countries with more stringent regulation (Tobey, 1990; Cole and Elliott, 2003; Levinson and Taylor, 2004).

On the other hand, the policy discourse is centred on the possibility of setting the economy on a "green growth" path. Proponents of this strategy worldwide hold that fostering reductions of harmful greenhouse gas emissions through environmental policy can be pursued together with increased growth and can result in higher competitiveness (Jaffe et al., 1995). For instance, Porter (1991) and Porter and Van der Linde (1995) claimed that well-crafted and well-enforced environmental regulation would benefit both the environment and the firm. Supporters of this view argue that environmental policy stringency will not harm competitiveness, but will benefit firms through increased innovation activity and improved productivity (Gray and Shadbegian, 
1993; Jaffe and Palmer, 1997; Lanoie et al., 2011; Ambec at al., 2013; Rubashkina et al., 2015; Albrizio et al., 2017; Dechezleprêtre and Sato, 2017).

Solid tests of these propositions are impaired by the lack of appropriate empirical proxies for the commitment to, and stringency of, environmental policy. Most of the studies on the impact of environmental policy on growth, productivity, and trade-related variables present conflicting results. This is due to three main reasons: (i) they differ in the sample of sectors/countries considered, (ii) they apply different empirical approaches and methodologies, and, last but not least, (iii) they use different proxies for the stringency of environmental policy. Such diversity makes it very hard to draw definite conclusions on the role and effectiveness of environmental policy.

In this paper we focus on the last issue and conduct an empirical investigation of whether different policy indicators convey overlapping or complementary information. This is an important question, which has implications for settling the debate around the impact of environmental policy on economic growth. If the different indicators proposed in the literature convey similar information, concerns about using one or the other indicator in empirical applications would be highly mitigated. Conversely, if these indicators convey different and complementary information, benefits can in principle be drawn by building a more general indicator capturing information from each of the components.

We proceed in three steps. First, we compute several of the policy indicators suggested in the literature. These include measures of pollution abatement efforts, composite policy indexes and emission-based indicators. Second, we compare them through a statistical analysis aimed to understand to what extent the various indicators convey similar/overlapping information. We concentrate on differences in average country rankings to show how the different indicators capture variations between countries. Third, we focus on differences in capturing within-country variation. To this end, we use the policy indicators in an application to assess to what extent 
empirical results obtained in a panel setting are indicator-dependent. Specifically, we test whether countries with more stringent environmental policy have indeed shown historically higher levels of environmental innovation or of energy efficiency. We carry out this analysis using panel data for 19 OECD countries over the years 1995-2009.

The results emerging from the statistical analysis show that the various environmental policy proxies do not always convey the same information with respect to either between-country or within-country variation. Generally speaking, in both cases indicators based on pollution abatement give rise to significantly different results than emission-based indicators or composite indexes. Overall, these two latter types of indicators show higher agreement.

The rest of the paper is organized as follows. Section 2 reviews the methodologies used in the empirical literature to proxy for the stringency of environmental policy and presents the indicators used in this paper. Section 3 shows the results of the comparison of the various indicators and of their relevance in empirical applications to environmental innovation and to energy efficiency. Section 4 closes the paper with some policy implications and directions for further research on the issue.

\section{Methods}

Measuring environmental policy stringency is a very difficult task, which is characterized by the standard challenges of building and implementing policy indicators. ${ }^{1}$ In this section we first discuss the methodological challenges which characterize the quantitative measurement of environmental policy stringency and describe broad groups of indicators which, notwithstanding such measurement challenges, have been implemented in the empirical economic literature to

\footnotetext{
${ }^{1}$ See for instance the discussions in Nourry (2008) and Selomane et al. (2015) with respect to indicators for sustainable development and social-ecological sustainability, respectively.
} 
date. We subsequently discuss the selection of indicators used in this paper, the methodology for their computation and the data sources.

\subsection{Methodological issues concerning the quantitative measurement of environmental policy stringency and available indicators}

Brunel and Levinson (2013) highlight the main challenges faced in any empirical analysis centered around the measurement of environmental policy stringency. First, countries can choose from a wide array of policy instruments to address climate and energy concerns. Each of these instruments is characterized by a different level of effectiveness, dynamic efficiency and political acceptability (Fisher and Newell, 2008). Hence, building a policy indicator requires facing this "multidimensionality" of a country's policy portfolio. Second, countries with worse pollution challenges might impose more stringent options. Not accounting for this would provide a biased indicator of environmental policy stringency. Third, some "initial condition" or some time varying characteristics, such as the industrial composition of the economy, the level of energy efficiency or the age of capital, might crucially affect the ability of countries to implement certain (lower cost) options. Finally, environmental policy is often endogenously determined. Notwithstanding these obstacles, several indicators have been proposed and applied in the literature. They can be grouped in four main categories: (a) pollution abatement effort, (b) direct assessments of regulations, (c) emission-based indexes, and (d) composite indicators. ${ }^{2}$

\subsubsection{Variables measuring pollution abatement efforts}

These include measures of both private and public effort. Pollution Abatement Costs and Expenditures (PACE) by private firms are among the most common indicators used. They are obtained from company surveys. The main criticism to such indicators is that they are subject to measurement errors, that they are potentially affected by reverse causality problems, and that in

\footnotetext{
${ }^{2}$ Brunel and Levinson (2013) identify five categories, by splitting our first category into private efforts (PACE) and government R\&D efforts.
} 
the presence of market or behavioral failures they do not successfully measure the level of regulatory pressure (Berman and Bui, 2001). Measures of government efforts to control pollution include environmental R\&D expenditures, total revenue from environmental taxes and the implicit tax rate on energy. These indicators gauge the commitment of governments to devote public money to the support of pollution or emission control. However, since this is only an indirect measure of government effort, this proxy has been less and less used as other direct measures, such as emissions and cost data, have become available. Note that both types of proxies are generally characterized by very poor country coverage, as we further discuss below.

\subsubsection{Direct assessments of regulations}

When dealing with very narrowly focused research questions, researchers have often resorted to specific proxies for environmental policy stringency. This approach becomes increasingly difficult as the focus of analysis widens. For instance, finding good proxies based on direct assessment of regulation at the sector or country level is difficult due to multidimensionality and simultaneity. An alternative widely used strategy in this category of proxies is to treat the US Clean Air Act as a natural experiment, since its standardized air quality limits (the NAAQS, National Ambient Air Quality Standards) address both problems above. Another example of a narrow regulation-based measure is the use of the lead content of gasoline as an indicator for overall environmental regulatory stringency.

\subsubsection{Composite indexes}

Some of the earliest examples of this type of indicator were based on simple indexes constructed from counts of regulations, non-governmental environmental organizations, international treaties signed, and similar variables. Another approach is to use statistical aggregation techniques, such as Principal Component Analysis, on a set of environmental policy 
indicators. More recently, approaches have been proposed to model environmental policy stringency as a latent variable, which we discuss more in detail below.

\subsubsection{Measures based on ambient pollution, emissions, or energy use}

Some studies have turned the question on its head and used emissions, ambient pollution, or energy use as measures of stringency. Early attempts in this direction used information about the level of (or the change in) emissions and energy use at the country or sector level. However, both changes and levels can differ across countries for many reasons other than environmental policy stringency, such as for instance differences in industrial composition and in the degree of trade openness. Furthermore, emission- or energy use-based indicators are also likely to mirror changes other than in regulatory stringency, such as for example in factor prices. To overcome these shortcomings, Brunel and Levinson (2013) refine this approach and propose an indicator which compares a country's predicted emissions intensity due to its sectoral composition (based on average emissions per sector worldwide) to the country's actual emission intensity. This indicator is larger (smaller) than one for countries whose actual emission intensity is higher (lower) than what would be expected given their sectoral composition. That is, the indicator is higher (lower) for countries with stricter (laxer) environmental policies. The Brunel and Levinson (2013) approach is more sophisticated than using the actual values of emission intensity per each country and year. As they highlight, such indicator comes a long way toward overcoming some of the shortcomings of previously proposed emission-based measures; specifically, it is theoretically motivated by pollution abatement costs, it is time-varying by country, and it accounts for a country's sectoral composition.

\subsection{Selection of indicators for this analysis}

In this paper, we compare insights from three of the above categories of indicators, namely: (i) variables measuring pollution abatement effort, (ii) composite indicators and (iii) emission- 
based indicators. ${ }^{3}$ The first type of indicator has been widely used in the past (especially PACE), notwithstanding the scattered data coverage. The second and the third types of indicators have recently become more and more popular due to increased data availability across a wide set of countries. Hence, these latter two types of indicators will increasingly be relevant for future assessments of the impact of environmental policy on economic growth. To the best of our knowledge, this paper represents the first attempt at comparatively assessing different indicators to measure environmental policy stringency.

For each category of indicators, we collect, compute and compare several proxies. This necessarily requires selecting different datasets. Combining the data availability of the various indicators, we are able to create a sample of at most 19 OECD countries over the years 19952009. The countries are: Austria, Australia, Belgium, Canada, Germany, Denmark, Spain, Finland, France, the United Kingdom, Greece, Hungary, Italy, Japan, Netherlands, Portugal, Sweden, Turkey, and the United States. ${ }^{4}$ We describe below each of the indicators in our analysis and provide insights on their development over time. Note that to make all indicators comparable in a straightforward way, we normalize them to lie between 0 and 10 by applying the transformation: $I^{n}=10 *\left(I-I_{\min }\right) /\left(I_{\max }-I_{\min }\right)$, where $I^{n}$ is the normalized indicator, $I$ is the indicator under consideration, and $I_{\min }$ and $I_{\max }$ are the lowest and the highest values of the indicator in our sample. ${ }^{5}$ Table 1 lists countries and environmental policy indicators considered and the corresponding abbreviations used throughout the paper. In the rest of this Section, we present and discuss each indicator and briefly comment on its time development for the countries in our sample.

\footnotetext{
3 "Natural experiment" approaches are useful but are hard to find in a cross-country setting.

${ }^{4}$ For the indicators measuring pollution abatement effort, poor data coverage causes our panel to be unbalanced. See the discussion later in the section.

5 This transformation leaves the statistical and empirical analysis we carry out unchanged but provides an easy visual way to compare the different indicators and to interpret the associated coefficients.
} 
[Table 1 about here]

\subsubsection{Proxies for pollution abatement effort}

We collect and compute four indicators to proxy for a country's pollution abatement efforts. The first indicator is computed as the share of Pollution Abatement Costs and Expenditures (PACE) in Gross Domestic Product (GDP). We denote it as $\mathrm{I}_{1}=\mathrm{PACE} / \mathrm{GDP}$. This indicator is retrieved from EUROSTAT (2015). Note that scaling the PACE variable by GDP is necessary, especially when carrying out cross country comparison, to account for the size of a given country's economy, which would determine differences in the ability to sustain PACE expenditures by firms. PACE is among the most popular early indicators of pollution abatement effort, notwithstanding the difficulties related to the use of expenditure data highlighted in the previous section. Nevertheless, it is important to include it in this analysis given the widespread use it has been subject to and the fact that many of the early findings based on this indicator are still very relevant today (see, for instance, Jaffe and Palmer 1997).

The second indicator is given by government expenditures on energy R\&D relative to GDP, denoted $I_{2}=R \& D / G D P$. Traditionally, energy R\&D investments have been among the most commonly used instruments to support the development of carbon-free and green technologies, with most countries introducing this form of support already in the early 1970s in the wake of the oil crisis (Haščič et al., 2010). We obtained energy R\&D data (in constant 2013 PPP US dollars) from the IEA Energy Technology R\&D Statistics Database (IEA, 2015), which provides information on government $R \& D$ expenditures in a number of important energy technologies. ${ }^{6}$ As done for previous indicator, government R\&D expenditures in energy are scaled by GDP (obtained from the National Accounts of OECD Countries, and transformed to

\footnotetext{
${ }^{6}$ The categories reported in the database include: fuel cells, fossil fuels power technologies, storage technologies, cross-cutting research, nuclear, energy efficiency, hydrogen, renewable energy and transport.
} 
constant 2013 PPP US dollars) to account for differences in the size of the economies considered.

The third indicator is the implicit tax rate on energy, denoted as $\mathrm{I}_{3}=$ ITRE. While taxing energy goods and services may simply be a way to collect revenues on a good with a relatively inelastic demand, the effect of a higher implicit tax rate is that of reducing energy consumption. Since most energy until recently was produced using fossil fuels, a higher tax would have de facto the same impact of a stringent environmental policy regulation, resulting in lower energy consumption and associated emissions. Data on the implicit tax rate on energy are taken from EUROSTAT (2015).

The fourth indicator we compute is the amount of total revenue from environmental and energy taxes as a share of GDP, denoted as $\mathrm{I}_{4}=\mathrm{TET} / \mathrm{GDP}$. Along the same lines of reasoning made above for the implicit tax rate on energy, higher revenues from environmental taxes relative to GDP would indicate a more stringent commitment towards environmental policy. Data on TET/GDP are downloaded from EUROSTAT (2015).

In Figure 1 we report the behavior across time and across countries of the four normalized pollution abatement effort indicators just described.

\section{[ Figure 1 about here]}

Significant heterogeneity is evident across the countries in our sample, both in terms of level and in terms of time profile. Only in a few cases the indicators show that stringency/commitment of policy has increased over time (for instance, ITRE and TET/GDP in the Netherlands or R\&D/GDP in Finland and Hungary). The four indicators convey a very similar picture only in the case of France. 


\subsubsection{Composite indicators}

We compute seven composite indicators of environmental policy stringency using the OECD Environmental Policy Stringency (EPS) database (Botta and Koźluk, 2014). The EPS database contains information on 15 different Non-Market Based (NMB) and Market Based (MB) environmental policy instruments implemented in OECD countries. NMB policies include limits to pollutants $\left(\mathrm{SO}_{\mathrm{x}}, \mathrm{NO}_{\mathrm{x}}\right.$, Particulate Matters and Sulphur Content of Diesel) and government energy-related R\&D expenditures as a percentage of GDP. MB policies include feed in tariffs (FIT) for solar and wind, taxes (on $\mathrm{CO}_{2}, \mathrm{SO}_{\mathrm{x}}, \mathrm{NO}_{\mathrm{x}}$ and Diesel), certificates (White, Green and $\mathrm{CO}_{2}$ ) and the presence of deposit and refund schemes (DRS). All variables in the database are continuous, except DRS which is a $0 / 1$ indicator for the presence of such schemes. Botta and Koźluk (2014) describe the methodology used to build this dataset: the reader is referred to their original contribution for details.

The first three composite indicators are the original OECD EPS indicators computed by Botta and Koźluk (2014), which we denote as $\mathrm{I}_{5}=$ EPS, $\mathrm{I}_{6}=$ MBEPS and $\mathrm{I}_{7}=$ NMBEPS. Details on the statistical procedure used for computation is available in the original publication. Here, we summarize its main steps. First, each of the continuous policy instrument of the database is categorized on a Likert scale from 0 to 6 using statistical procedures to identify specific bins. These 15 Likert-scale scores are then aggregated into 6 large macro-instruments: Taxes, Certificates, Limits, FIT, DRS and R\&D by using weights. Subsequently, these 6 indicators are aggregated into a MBEPS score (Taxes, Certificates, FIT, DRS) and a NMBEPS score (R\&D and Limits). The EPS composite score is then obtained as the average between the MBEPS and NMBEPS scores.

The fourth and fifth composite indicators are computed following the approach adopted in Nesta et al. (2014). Specifically, based on the detailed data included in the OECD EPS database, a score of 1 is assigned to a country starting from the year in which it first implements a given 
policy instrument. The composite policy indicator is then computed by summing the different dummy indicators for each country and year. We build a first indicator, labelled as $\mathrm{I}_{8}=\mathrm{SUM} 15$, which can range from 0 to 15 , considering the 15 continuous variables contained in the OECD EPS database. We build a second indicator, denoted as $\mathrm{I}_{9}=\mathrm{SUM} 6$, which can range from 0 to 6 , considering the 6 categorical macro-aggregates proposed by Botta and Koźluk (2014) and described above. These two indicators inform on the diversification of the policy portfolio in a given country over time.

The sixth and seventh composite indicators are computed following the method proposed in Galeotti et al. (2018). Also in this case we briefly summarize the methodology and refer the reader interested in details to the original publication. Building on an approach common in Item Response Theory, Galeotti et al. (2018) propose an ordinal logistic three-level random intercept (TLRI) model to assess the performance of countries with respect to environmental policy, which is treated as a latent variable. In the TRLI context, the levels considered are "policy instrument" (level 1), "time" (level 2) and "country" (level 3). Relative to the basic IRT model that considers two levels (the item, or policy instrument, and the subject, or the country), Galeotti et al. (2018) set up a three-level random intercept model accounting for a third dimension of their dataset, which is time. We apply this methodological approach where we use the continuous data on the 15 policy instruments in the OECD EPS Database to estimate the TLRI model. After estimating the TLRI, we sum the third ("country") and second level ("time") residuals to obtain a time-varying indicator of a country's commitment to stringent environmental policy, which we label $\mathrm{I}_{10}=$ LATENT15. We repeat the same procedure using the data on the 6 categorical aggregates used in Botta and Koźluk (2014) to obtain $\mathrm{I}_{11}=$

\section{LATENT6.}


Figure 2 and Figure 3 show the time profile of the normalized composite indicators described above. Specifically, Figure 2 shows the time profile of the EPS, MBEPS and NMBEPS. Figure 3 shows the time profiles of the SUM6, SUM15, LATENT6 and LATENT15 variables.

[ Figure 2 about here]

[Figure 3 about here]

Note that in this case, unlike the case of the proxies for pollution abatement effort, the indicators convey very similar information, both with respect to level and time profile. From Figure 2, it is evident that the EPS variable is the average of its components, MBEPS and NMBEPS. Figure 3 shows that the SUM6 and SUM15 indicators provide less variability with respect to the LATENT6 and LATENT15 indicators. .

\subsubsection{Emission-based indicators}

We compute two emission-based indicators using data on sectoral emissions which is taken from the World Input-Output Database (WIOD, 2013; Timmer et al. 2015). The first, which we denote $\mathrm{I}_{12}=\mathrm{BL} \_\mathrm{CO} 2$, is based on the methodology proposed by Brunel and Levinson (2013) and calculated as the ratio of the predicted $\mathrm{CO}_{2}$ emission intensity to the actual emissions intensity of a given country, as explained above. ${ }^{7}$ To this end, we use data on carbon dioxide emissions in Kilotons aggregated across 26 energy carriers and data on value added by sector

\footnotetext{
${ }^{7}$ Readers interested in the detailed discussion of this indicator are referred to the original Brunel and Levinson (2013) paper.
} 
expressed in monetary units in 1995 prices and then converted to million US dollars using market exchange rates. ${ }^{8}$

In addition to including information on $\mathrm{CO}_{2}$ emissions, WIOD also collects data on other pollutants: sulfur oxide $\left(\mathrm{SO}_{\mathrm{x}}\right)$, Nitrogen oxide $\left(\mathrm{NO}_{\mathrm{x}}\right)$, non-methane volatile organic compounds (NMVOC), ammonia $\left(\mathrm{NH}_{3}\right)$, nitrous oxide $\left(\mathrm{N}_{2} \mathrm{O}\right)$, carbon monoxide $(\mathrm{CO})$, methane $\left(\mathrm{CH}_{4}\right)$. The second emission-based indicator, denoted $\mathrm{I}_{13}=$ BL_PCA, exploits information on all these pollutants and is computed in two steps. First, we calculate a Brunel-Levinson indicator for each pollutant. Second, we apply a Principal Component Analysis (PCA) approach to all these indicators. PCA allows to successfully summarize several variables (in this case, emissionsbased indicators) through a synthetic statistic. Specifically, PCA reduces a number of (possibly) correlated variables (representing as many characteristics of the analyzed phenomenon) to a (smaller) number of latent variables called principal components. In PCA, the first principal component accounts for as much of the variability in the data as possible and each subsequent component accounts for as much of the remaining variability as possible. Such an approach has been proposed, for example, in Vona and Nicolli (2012) to summarize the presence of several policy instruments at the country level. The analysis indicates that the first components accounts for most of the variability in the data (almost 51 percent) and is positively correlated with all the underlying indicators. ${ }^{9}$ Hence, the first component can be reasonably used as a summary measure for all emission-related indicators.

Figure 4 shows the time profiles for the BL_CO2 and the BL_PCA indicators, which generally behave quite similarly, both in terms of absolute values and time profiles.

\footnotetext{
${ }^{8}$ Note that the most recent version of the WIOD Database, which was published in 2016, does not contain data on "environmental accounts", namely the input-output tables of $\mathrm{CO}_{2}$ emissions and other pollutants. For this reason, we are forced to rely on the WIOD (2013) version of the database, which is the only data source that provides statistical information for several countries and time periods at the sectoral level, including environmental accounts. This version of the database covers the period from 1995 to 2009 (WIOD, 2013).

${ }^{9}$ The detailed results of the PCA analysis are available from the authors upon request.
} 
[Figure 4 about here]

Country-level averages over the sample period for all normalized indicators are presented in Table 2. As already mentioned, information about all these indicators is missing for some countries in some years due to missing data.

[Table 2 about here]

\section{Results}

In this section, turn to the comparison of the indicators presented above. We are interested in understanding to what extent the information they convey is similar. There are two important aspects of this question that need to be addressed: differences between countries and differences within countries. Understanding if the different indicators provide a consistent representation of these two aspects is necessary to gauge the extent to which researchers can rely on any indicator or whether this choice will affect the results of any (empirical) analysis. We explore the issue of between-country variations in Section 3.1 through a statistical analysis of the average country rankings which emerge in the sample. Insights emerging from this comparison are relevant both to summarize the performance of countries over specific periods of times, and when considering cross-sectional differences and analysis. The second issue, namely differences in the ability to capture within-country variations over time, is explored in Section 3.2 where we present two empirical applications in a panel setting.

\subsection{Results from between-country variation}


We begin by looking at between-country variation, which is tantamount to asking whether, on average, all policy indicators attribute a similar score to each country, i.e. they give rise to similar country rankings. This is an important issue for two reasons. First, there is the interest in ranking countries with respect to their ability to implement environmental policies. This is, for instance, the aim of the OECD policy indicator as presented on the OECD website, where nice figures are shown that rank all OECD countries from the worse to the best performer. Clearly, if different indicators give rise to similar rankings, then such rankings are rather robust. Conversely, if the rankings are sensitive to the choice of indicator then no robust conclusions can be drawn in this respect. Second, the agreement or disagreement of country rankings for different indicators has significant implications for any cross-sectional empirical analysis, which exploits between-country variations to identify the relevant coefficient.

The rankings we present here are built using information on the average value of the specific indicator for each country over the sample period. The Spearman correlation, reported in Table 3 , shows that the indicators are generally positively correlated with each other. There is only one case of negative correlation, between ITRE and BL_CO2. As evidenced from Figure 1, the correlation among the pollution abatement efforts indicators is rather low, while it is higher among the composite indicators and between the BL_CO2 and the BL_PCA indicators. Overall, the indicators that display higher average correlations are LATENT6 and LATENT15.

[Table 3 about here]

Based on the average value over the sample period for each indicator we produce country rankings, which are displayed in Table 4 and in Figure 5, which confirm once again that the different indicators are not in agreement. In Table 4 we visually represent the rankings for each 
country and indicator of environmental policy stringency with colors that go from white to dark green: the lowest level of environmental policy stringency is assigned a white color, whereas the highest level a dark green color. In Figure 5, the bigger the slice of the pie, the higher the ranking of the given country for the given indicator.

[Table 4 about here]

[Figure 5 about here]

Generally speaking, the agreement is higher between the composite and emission-based indicators, while the indicators based on pollution abatement give rise to significantly different country rankings. In some cases (for instance Belgium, Denmark and Germany), the position of countries is generally stable across indicators. In other cases (for instance, Canada and Greece), using different indicators can give rise to completely different insights. These differences may reasonably hide differences in the effectiveness of policy implementation and monitoring, or the fact that some indicators do not take into account the "intensity" of the implemented policies (this is the case for the SUM6 and SUM15 indicators, which have often been used in the literature). Furthermore, in the case of the SUM6 and SUM15 indicators, it can be argued that it is indeed the countries with lowest performance (i.e. low ranking in emission-based or pollution effort indicators) that need to implement a more complex portfolio of policy instruments to address pressing environmental issues. If a country is already doing well, further regulation may be needed less. This reasoning does not however apply to the EPS and other composite indicators, which take into account the stringency of the implemented policy. 
To further characterize the distance between these metrics, Figure 6 presents a dendogram, a tree diagram frequently used to illustrate the arrangement of the clusters produced by hierarchical clustering. In the dendrogram, each indicator is positioned according to its distance with the other indicators. Indicators with higher similarity cluster into nodes. The height indicates how far away the indicators within the different clusters are. Specifically, the height of each node in the plot is proportional to the value of the intergroup dissimilarity between its two whiskers.

Consistent with what presented above, the dendogram shows that the several composite indexes we compute are closer to each other than they are to emission-based indicators or to the indicators measuring pollution abatement effort. Interestingly, PACE/GDP and R\&D/GDP are rather close to each other, indicating that in general public and private measures of pollution abatement effort provide consistent country rankings. SUM6 and SUM15 indicators are very similar, as are the BL_CO2 and the BL_PCA metrics and the EPS and MBEPS ones.

The statistical analysis presented to so far has shown that the country rankings are not robust to the choice of indicator. This is particularly troublesome if such indicators where to be applied in cross-sectional analysis of between-country differences, as they would give rise to different results. We now explore whether this holds true when analyzing within-country variations in a panel setting through two empirical applications.

[Figure 6 about here]

\subsection{Results from within-country variation}

Another crucial dimension of the comparison of alternative indicators of environmental policy stringency is whether they capture similar or different dynamics of within-country variations. 
Specifically, the relevant question in this respect is whether the different indicators display similar time profiles within each country. If this were the case, for instance, empirical analyses in a panel setting (which exploit within-country variations of the variables of interest) would provide similar results irrespective of the indicator used. This issue is best studied through empirical applications which highlight how the different indicators perform in practice.

Indeed, in many cases empirical analyses of the effectiveness of environmental policies presents conflicting results. As argued in the Introduction, for instance, this is the case for analyses focused on economic performance and competitiveness or on innovation. One is thus left to wonder whether such differences are indeed real, which would mean that environmental policy has somewhat of an idiosyncratic effect, or whether they depend more on empirical design and specifically on the choice of proxy for policy stringency.

In this Section, we shed light on this issue by studying whether the implications of using one or the other indicator influence the results of empirical analyses. Specifically, we focus on two examples which have been widely studies in the literature. First, we assess whether countries with more stringent environmental and energy policy perform better in terms of environmental innovation. Second, we focus on the impact of energy and environmental policies on improvements in the efficiency with which energy inputs are used. ${ }^{10}$ Both environmental innovation and energy efficiency are arguably affected by the implementation of energy and environmental policies, as discussed in a large literature (see for a discussion Carraro et al., 2010; Popp et al., 2010; Witajewski-Baltvilks et al., 2017; Popp, 2019). Overall, both variables are expected to be positively associated with higher values of the policy indicators presented above, since environmental regulation, primarily motivated by energy-related emission control, is in principle able to foster technological innovation, to provide stimuli for consumers to

\footnotetext{
${ }^{10}$ Increased energy efficiency encompasses improvements in existing energy technologies, introduction and diffusion of new technologies, more modern and advanced infrastructure networks, more rational use of energy.
} 
efficiently use energy, to generate incentives for investment in better and more efficient infrastructures. The efficiency of energy use should therefore be enhanced by effective environmental policies.

\subsubsection{Environmental innovation}

As mentioned in the Introduction, the role of environmental policy can be framed within the socalled Porter Hypothesis, which holds that environmental policy stringency will not harm competitiveness, but will benefit firms through increased innovation activity and improved productivity. ${ }^{11}$ With respect to innovation, Hick's (1932) induced innovation hypothesis posits that both increased demand and increased technological opportunity in a given country affect the production of additional knowledge. Popp (2002) confirms this insight in his analysis of innovation in energy technologies in the United States.

To investigate the role of environmental policy on innovation, following Jaffe and Palmer (1997) and Rubashkina et al. (2015), we adopt a simple log-log specification relating innovation to an environmental policy indicator and to a few controls capturing demand and supply determinants of knowledge, so that:

$$
\ln P A T R_{c t}=\alpha_{c}+\alpha_{t}+\beta_{1} \operatorname{lnGDP} P_{c t}+\beta_{2} \ln K P A T R_{c t}+\beta_{1} P E_{c t}+\beta_{1} I_{(n) c t}+u_{c t}
$$

In (1) the ratio between environmental patents to total patents $(P A T R)$ in country $c$ at time $t$ is taken to depend on real per capita GDP, on the ratio between the stock of environmental patents to the total patent stock (KPATR), an energy price index $(P E)$, and the selected environmental policy stringency indicator $\left(I_{(n)}, n=1, \ldots, 12\right)$, as denoted in the previous section (see also Table 1). Patent data are downloaded from the OECD (2015) Patents Statistics database; they

\footnotetext{
${ }^{11}$ See Dechezleprêtre and Sato (2017) for a recent critical review.
} 
represent applications to the European Patent Office assigned according to inventor country. Data on GDP are expressed in US dollars in 2005 PPP prices and are drawn from the National Accounts of OECD Countries. The energy price index is the real end-use energy price index $(2010=100)$ for households and industry provided by the IEA Energy Prices and Taxes Database (2015). We include per capita GDP as a proxy for the resources necessary to meet the fixed costs and bear the risks involved with undertaking investments in innovation. Demand-pull effects are proxied by energy prices, as price changes affect a firm's decision regarding R\&D investment and efforts, thus influencing the rate and direction of innovation and resulting in biased technological change. To allow for technology push factors, we add a knowledge stock variable capturing previous innovation experience, which is expected to have a positive influence on the innovation capacity because innovators can "stand on the shoulders of the giants”. Higher past investment in technological development makes it more likely to engage in future innovative practices. We consider both the contemporaneous and the once lagged policy indicator, in the latter case to avoid simultaneity problems with innovation activity. We allow for country $(c)$ and time $(t)$ fixed effects, represented by $\alpha_{c}$ and $\alpha_{t}$ respectively, $u_{c t}$ is a standard error term. The results are presented in Table $5 .^{12}$

[Table 5 about here]

All regressions reported in both panels show good fits and significant and correctly signed control variables. The energy price index presents a few occasional exceptions. Focusing on the environmental policy indicators and looking at their statistical significance, we note that those capturing pollution abatement efforts are all insignificant. The set of composite indicators is, on

\footnotetext{
${ }^{12}$ We should like to point out that this and the following application are essentially illustrative. The results cannot therefore be generalized. In addition, we rely on "standard" specifications of the literature, with no special ambition to look for the best statistical fit.
} 
the contrary, almost always statistically significant, with the notable exception of the SUM15 index. If they are entered lagged once, however, the statistical significance fades away. The Brunel-Levinson indicators are significant only lagged once. Turning to the sign of the coefficients, all the significant cases are positive, in agreement with the (weak version of the) Porter hypothesis: thus, an increase in the stringency of environmental policy prompts firms to undertake more environmental innovation relative to the total. How large is this incentive effect? The size of the impact is generally similar and small: given that our indicators are normalized, our findings suggest that a 10 percent increase in any of the significant index (which is equivalent in our case to a 1 unit increase) would result in an increase of environmental patenting relative to total patents of about 0.2 to 0.4 percent (one BrunelLevinson indicator is equal to 0.8 ).

\subsubsection{Energy efficiency}

Energy economists have shown a long-standing interest in the study of aggregate reduced form relationships between economic development and energy demand, both for positive and normative purposes (among many others: Zilberfarb and Adams, 1981; Galli, 1998; Judson et al., 1999; Medlock and Soligo, 2001; Ozturk, 2010; Stern, 2011; Csereklyei et al., 2014; Tiba and Omri, 2017; Shahbaz et al., 2018). One aspect with relevant policy implications is whether the income elasticity of energy consumption is below one. If confirmed by empirical evidence, this result would imply the progressive decoupling of energy use from economic growth, with very important consequences for energy-related emissions of carbon dioxide and thus climate change. Moreover, in resource-poor countries energy dependence from abroad may provide a powerful stimulus to economize on energy. More generally, and independently of environmental considerations, conserving energy contributes to lessening the pressure on exhaustible resource depletion. 
To deal with the above issues it is convenient to model a variable income elasticity of aggregate energy consumption, so that as income increases the elasticity may decrease and even turn negative (Richmond and Kaufmann, 2006; Howarth, Galeotti, Lanza, and Dubey, 2017). This would imply energy efficiency improvements given by the negative correlation between energy use and GDP. These improvements can be fostered by energy and environmental policy. ${ }^{13}$ The standard approach is to assume that per capita energy consumption $(E / P)$ is a function of (real) per capita income $(G D P / P)$ and of other controls. To capture the possibility that the income elasticity of energy use may first increase and then decrease as income goes up the square of per capita GDP is added to the right hand side of the relationship. The usual parametrization of the energy-income relationship is a log-linear polynomial function of income:

$$
\ln (E / P)_{c t}=\delta_{c}+\delta_{t}+\gamma_{1} \ln (G D P / P)_{c t}+\gamma_{2}[\ln (G D P / P)]_{c t}^{2}+\gamma_{3} I_{(n) c t}+e_{c t}
$$

where for simplicity the only additional controls are our alternative indicators of environmental policy stringency $\left(I_{(n)}, n=1, \ldots, 12\right)$ and where country-specific and time-specific effects have been allowed for. These are given by $\delta_{c}$ and $\delta_{t}$ respectively, while $e_{c t}$ is a standard error term. Note that, in keeping with the concept of energy efficiency, we can exploit the logarithmic properties of (2) and reformulate it with energy intensity $(E / G D P)$ as a function of per capita GDP. That is:

$$
\ln (E / G D P)_{c t}=\delta_{c}+\delta_{t}+\theta_{1} \ln (G D P / P)_{c t}+\theta_{2}[\ln (G D P / P)]_{c t}^{2}+\theta_{3} I_{(n) c t}+e_{c t}
$$

\footnotetext{
${ }^{13}$ In the electricity sector the link between efficiency and regulation has been studied by several authors: one very recent example is Bigerna et al. (2019).
} 
We estimate (3) using data on Total Final Energy Consumption $(E)$ - measured in Mtoe - taken from IEA World Energy Statistics and Balances (various years), whereas population $(P)$ and GDP in US dollars in 2005 PPP prices data are from the National Accounts of OECD Countries. We use these data together with the environmental policy indicators described above on our sample which covers the period 1995-2009 for the 19 countries under examination. A within estimator econometric method is used.

Note that energy efficiency improvements are possible only in a context of economic growth. Indeed, growth implies an increased demand for environmental protection, while making it possible to allocate the financial resources necessary for implementing those changes in energy systems. Thus, economic growth entails per se an increase in total energy use, as increased production volumes require more energy, but also allows for a more rational use that may even result eventually in a lower energy intensity of the economy. This is presumably where environmental policies play a role.

The results are presented in Table 6. As before, the policy indicator is entered either current or lagged, on the account of issues of potential endogeneity.

[Table 6 about here]

Focusing first on the relationship between energy intensity and income, we see that all GDP coefficients are highly significant and the signs are as expected. Geometrically speaking, the relationship is concave or, equivalently, the income elasticity of energy consumption is initially positive and then becomes negative, implying absolute decoupling between energy use and economic growth. 
Focusing on environmental policy indicators and looking first at their statistical significance, a clear pattern can be seen. Indicators capturing pollution abatement efforts are generally insignificant, with the notable exception of the implicit tax rate of energy (ITRE). The set of composite indicators is, on the contrary, almost always statistically significant, with the notable exception of the market-based OECD policy indicator (MBEPS). Finally, of the two BrunelLevinson indicators considered, only the $\mathrm{CO}_{2}$ emissions-based indicator is significant, whereas the indicator based on the PCA of various pollutants is never significant. Turning to the sign of the coefficients, in nearly all cases they are negative as expected, implying that the overall shape of the energy intensity - income relationship shifts downward as a consequence of more stringent environmental policies, thus bringing about an improvement in the economy's energy efficiency. Furthermore, composite and emission-based indicators generally provide a similar picture, suggesting that a 10 percent increase in policy commitment/stringency leads to a reduction of between 0.5 and 1.5 percent in energy intensity. The only notable case of a positive and significant coefficient is that of total revenue from environmental and energy taxes as a share of GDP (TET/GDP), which is difficult to rationalize. ${ }^{14}$

\section{Conclusion and Policy Implications}

Effectiveness of economic policies is a critical requirement for policy makers to be able to achieve the desired goals. While this condition is often taken for granted by policy studies, policy measures may be more or less effective depending on their degree of stringency. Increasing concerns about the adverse impacts of global warming and climate change worldwide are inducing more and more governments to take concrete mitigation actions. To this end, countries are implementing increasingly stringent environmental policies aimed to curb

\footnotetext{
${ }^{14}$ The lack of significance of the BL_PCA indicator is hardly surprising given the results of the PCA analysis form which it is built. In particular, the BL_PCA indicator represents the first Principal Component, which in the case at hand captures only half of the variation across the different indicators. See Appendix B.
} 
emissions of greenhouse gases. This shift is however accompanied by concerns that increased environmental policy stringency may come at the expense of competitiveness and well-being, especially in light of the recent economic downturn. To empirically assess these impacts, it is important to have appropriate empirical proxies for the commitment to, and stringency of, environmental policy. Unfortunately, there is no unique indicator of such policy, but the literature has proposed several alternatives.

This paper has presented several indicators of environmental policy stringency proposed in the literature, which include indicators measuring pollution abatement effort by both the public and the private sectors, composite indicators and emission-based indicators. We conducted an empirical investigation of whether different policy indicators convey overlapping or complementary information. This is an important question, which has implications for the analysis of environmental policy impact on economic growth. If the different indicators proposed in the literature convey similar information, concerns about using one or the other indicator in empirical applications would be highly mitigated. Conversely, if, as we might expect, these indicators convey different and complementary information, benefits can in principle be drawn by building a more general indicator capturing information from each of the components. In our comparative analysis we analyzed how such indicators capture betweencountry variations by focusing on the difference in average rankings over the sample period. It also shed some light on whether they differ in capturing within-country variation through two illustrative empirical applications, on environmental innovation and on energy efficiency respectively.

The analysis presented in this paper shows that conclusions regarding within-country or between-country variation are not robust across the different indicators considered. More specifically, both with respect to within-country and between-country variation there is higher agreement between composite and emission-based indicators, while proxies based on pollution 
abatement effort paint a very different picture. This confirms that part of the disagreement with respect to several important question in the empirical literature are likely the result of a different choice in policy indicators.

The analysis presented in the paper thus points to some fruitful future research directions. First, methodologies should be devised to appropriately summarize the several environmental policy indicators into one summary statistics for use in aggregate assessments of the impact of environmental policy on economic growth and performance. Second, attention should be devoted to the quantification of differences emerging from the various indicators. Thirdly, additional empirical applications should be considered. In this direction we are currently focusing our research efforts.

\section{Acknowledgements}

This paper was prepared within the "Value Added in Motion (VAM)" project, funded by the Enel Foundation, through Centro Studi Luca D'Agliano. We are grateful to Arik Levinson, Reyer Gerlagh, and Francesco Vona for comments on a previous version of the paper.

\section{References}

Albrizio, S., Kozluk, T., Zipperer, V. 2017. Environmental policies and productivity growth: Evidence across industries and firms. Journal of Environmental Economics and Management 81(C), 209-226. https://doi.org/10.1016/j.jeem.2016.06.002.

Ambec, S., Cohen, M.A., Elgie, S., Lanoie, P. 2013. The Porter hypothesis at 20: can environmental regulation enhance innovation and competitiveness?. Review of Environmental Economics and Policy 7, 2-22. http://dx.doi.org/10.2139/ssrn.1754674. 
Berman, E., Bui, L. T. M., 2001. Environmental regulation and productivity: evidence from oil refineries. Review of Economics and Statistics 83 (3), 498-510. http://www.mitpressjournals.org/doi/pdf/10.1162/00346530152480144.

Bigerna, S., D'Errico, M.C., Polinori, P., 2019. Environmental and energy efficiency of EU electricity industry: An almost spatial two stages DEA approach. The Energy Journal 40(SI1). https://doi.org/10.5547/01956574.40.SI1.sbig.

Botta, E., Koźluk, T., 2014. Measuring environmental policy stringency in OECD countries: a composite index approach. OECD Economics Department Working Paper N. 1177, http://dx.doi.org/10.1787/5jxrjnc45gvg-en.

Brunel, C., Levinson, A., 2013. Measuring environmental regulatory stringency. OECD Working Paper N. 2013/05, http://dx.doi:10.1787/18166881.

Carraro, C., De Cian, E., Nicita, L., Massetti, M., Verdolini, E., 2010, Environmental Policy and Technical Change: A Survey. International Review of Environmental and Resource Economics 4, 163-219. http://dx.doi.org/10.1561/101.00000033.

Cole, M., Elliot, R., 2003. Do environmental regulations influence trade patterns? testing old and new trade theories. The World Economy 26 (8), 1163-1186. https://doi.org/10.1111/1467-9701.00567.

Csereklyei, Z., Rubio-Varas, M., Stern, D.I., 2014. Energy and economic growth: the stylized facts. CCEP Working Paper No. 1417.

De Boeck, P., Wilson, M., 2004. A framework for item response models. In: Explanatory item response models. A generalized linear and nonlinear approach, P. De Broeck and M. Wilson (eds), New York: Springer, 3-41. https://doi.org/10.1007/978-1-4757-3990-9_1. 
Dechezleprêtre, A., Sato, M., 2017. The impacts of environmental regulations on competitiveness. Review of Environmental Economics and Policy 11, 183-206. https://doi.org/10.1093/reep/rex013.

EUROSTAT 2015. Eurostat Database, available at http://ec.europa.eu/eurostat/data/database.

Fisher, C., Newell, R., 2008. Environmental and technology policies for climate mitigation. Journal of Environmental Economics and Management 55, 142-162. https://doi.org/10.1016/j.jeem.2007.11.001.

Galeotti, M., Rubashkina, Y., Salini, S., Verdolini, E., 2018. Environmental policy performance and its determinants: Application of a three-level random intercept model. Energy Policy 114, 134-144. https://doi.org/10.1016/j.enpol.2017.11.053.

Galli, R., 1998. The Relationship between Energy Intensity and Income Levels: Forecasting Long Term Energy Demand in Asian Emerging Countries. Energy Journal 19, 85-105. DOI: 10.5547/ISSN0195-6574-EJ-Vol19-No4-4.

Gray, W.B., Shadbegian R., 1993. Pollution abatement costs, regulation, and plant-level productivity. NBER Working Paper N. 4994.

IEA 2015. Energy Technology RD\&D Statistics Database, available at www.oecd.org.

Haščič, I., Johnstone N., Watson F., Kaminker C., 2010. Climate policy and technological innovation and transfer: An overview of trends and recent empirical results. OECD Environment Working Papers N.30, OECD Publishing. http://dx.doi.org/10.1787/5km33bnggcd0-en.

Howarth, N., Galeotti, M., Lanza, A., Dubey, K., 2017. Economic development and energy consumption in the GCC: an international sectoral analysis. Energy Transitions 1, 1-19. https://doi.org/10.1007/s41825-017-0006-3. 
Hicks, J.R., 1932. The Theory of Wages, London: Macmillan and Co.

Jaffe, A.B., Peterson S.R., Portney, P.R., Stavins, R.N., 1995. Environmental regulations and the competitiveness of U.S. manufacturing: what does the evidence tell us?. Journal of Economic Literature, 33, 132-163.

Jaffe, A., Palmer, K., 1997. Environmental regulation and innovation: a panel data study. Review of Economics and Statistics 79 (4), 610-619. DOI: 10.1162/003465397557196.

Judson, R.A., Schmalensee, R., Stoker, T.M., 1999. Economic Development and the Structure of Demand for Commercial Energy. Energy Journal 20, 29-57. DOI: 10.5547/ISSN01956574-EJ-Vol20-No2-2.

Lanoie, P., Laurent-Lucchetti, J., Johnstone, N., Ambec S., 2011. Environmental policy, innovation and performance: new insights on the Porter hypothesis. Journal of Economics \& Management Strategy 20, 803-842. https://doi.org/10.1111/j.1530-9134.2011.00301.x.

Levinson, A., Taylor S., 2004. Unmasking the pollution haven effect. International Economic Review 49(1), 223-254. https://doi.org/10.1111/j.1468-2354.2008.00478.x.

Medlock, K. B., Soligo, R., 2001. Economic Development and End-Use Energy Demand. Energy Journal 22, 77-105. DOI: 10.5547/ISSN0195-6574-EJ-Vol22-No2-4.

Nesta, L., Vona, F., Nicolli, F., 2014. Environmental policies, competition and innovation in renewable energy. Journal of Environmental Economics and Management 67(3), 396-411. https://doi.org/10.1016/j.jeem.2014.01.001.

Nourry, M. 2008. Measuring sustainable development: Some empirical evidence for France from eight alternative indicators, Ecological Economics 67, 441-456. https://doi.org/10.1016/j.ecolecon.2007.12.019. 
OECD (2015). Environment Statistics: Innovation in environment-related technologies, Technology development. https://stats.oecd.org/, downloaded 22/07/2015.

Ozturk, I., 2010. A literature survey on energy-growth nexus. Energy Policy 38(1), 340-349. https://doi.org/10.1016/j.enpol.2009.09.024.

Popp, D., 2002. Induced innovation and energy prices. American Economic Review 92 (1), 160180. DOI: $10.1257 / 000282802760015658$.

Popp, D., 2019. Environmental Policy and Innovation: A Decade of Research, NBER Working Paper No. 25631. DOI: 10.3386/w25631.

Popp, D., Newell, R.G., Jaffe, A.B., 2010. Energy, the Environment, and Technological Change, In Bronwyn H. Hall and Nathan Rosenberg: Handbook of the Economics of Innovation, Volume-II, Burlington: Academic Press, 2010, 873-938.

Porter, M., 1991. America's green strategy. Scientific American 264, 168.

Porter, M.E., van der Linde, C., 1995. Towards a new conception of the environmentalcompetitiveness relationship. Journal of Economic Perspectives 9, 97-118. DOI: 10.1257/jep.9.4.97.

Richmond, A.K., Kaufmann, R.K., 2006. "Is there a turning point in the relationship between income and energy use and/or carbon emissions?. Ecological Economics 56, 176-189. https://doi.org/10.1016/j.ecolecon.2005.01.011.

Rubashkina, Y., Galeotti, M., Verdolini, E., 2015. Environmental regulation and competitiveness: empirical evidence on the Porter hypothesis from European manufacturing sectors. Energy Policy 83, 288-300. https://doi.org/10.1016/j.enpol.2015.02.014. 
Selomane, O., Reyers, B, Biggs, R., Tallis, H., Polasky, S., 2015. Towards integrated socialecological sustainability indicators: Exploring the contribution and gaps in existing global data. Ecological Economics 118, 140-146. https://doi.org/10.1016/j.ecolecon.2015.07.024.

Shahbaz, M., Zakaria, M., Shahzad, S.J.H., Mahalik, M.K., 2018. The energy consumption and economic growth nexus in top ten energy-consuming countries: Fresh evidence from using the quantile-on-quantile approach. Energy Economics 71(C), 282-301. DOI: 10.1016/j.eneco.2018.02.023.

Stern, D. I., 2011. The role of energy in economic growth. Annals of the New York Academy of Sciences 1219(1), 26-51. https://doi.org/10.1111/j.1749-6632.2010.05921.x.

Tiba, S., Omri, A., 2017. Literature survey on the relationships between energy, environment and economic growth. Renewable and Sustainable Energy Reviews, 69, 1129-1146. https://doi.org/10.1016/j.rser.2016.09.113.

Timmer, M. P., Dietzenbacher, E., Los, B., Stehrer, R. and de Vries, G. J. (2015), "An Illustrated User Guide to the World Input-Output Database: the Case of Global Automotive Production", Review of International Economics., 23: 575-605. https://doi.org/10.1111/roie.12178.

Tobey, J., 1990. The effects of domestic environmental policies on patterns of world trade: an empirical test. Kyklos 43 (2), 191-209. https://doi.org/10.1111/j.1467-6435.1990.tb00207.x.

Verdolini, E., Galeotti, M., 2011. At home and abroad: An empirical analysis of innovation and diffusion in energy technologies. Journal of Environmental Economics and Management 61, 119-134. https://doi.org/10.1016/j.jeem.2010.08.004.

Vona, F., Nicolli, F., 2012. The evolution of renewable energy policy in OECD countries: aggregate indicators and determinants. FEEM Nota di Lavoro No. 2012/051.

WIOD, 2013. World Input-Output Database, February 2012 Release.

World Bank, 2013. The World Bank, World Development Indicators. 
Witajewski-Baltvilks, J., Verdolini, E., Tavoni, M., 2017. Induced technological change and energy efficiency improvements. Energy Economics 68(S1), 17-32. https://doi.org/10.1016/j.eneco.2017.10.032.

Zilberfarb, B.-Z., Adams, F.G., 1981. The Energy-GDP Relationship in Developing Countries: Empirical Evidence and Stability Tests. Energy Economics 3, 244-248. https://doi.org/10.1016/0140-9883(81)90025-6. 


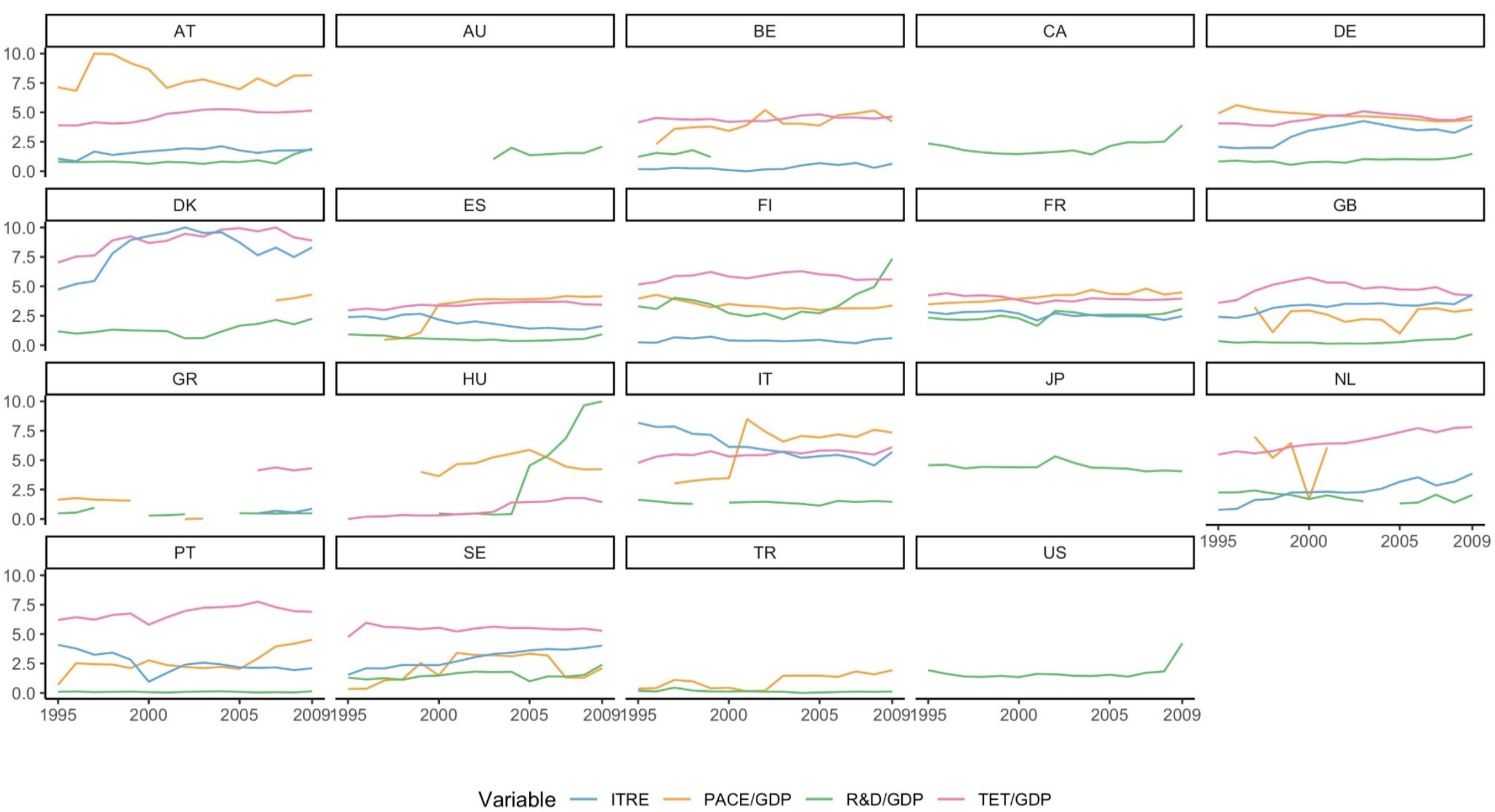

Fig. 1. Proxies for pollution abatement effort, 1995-2009. 


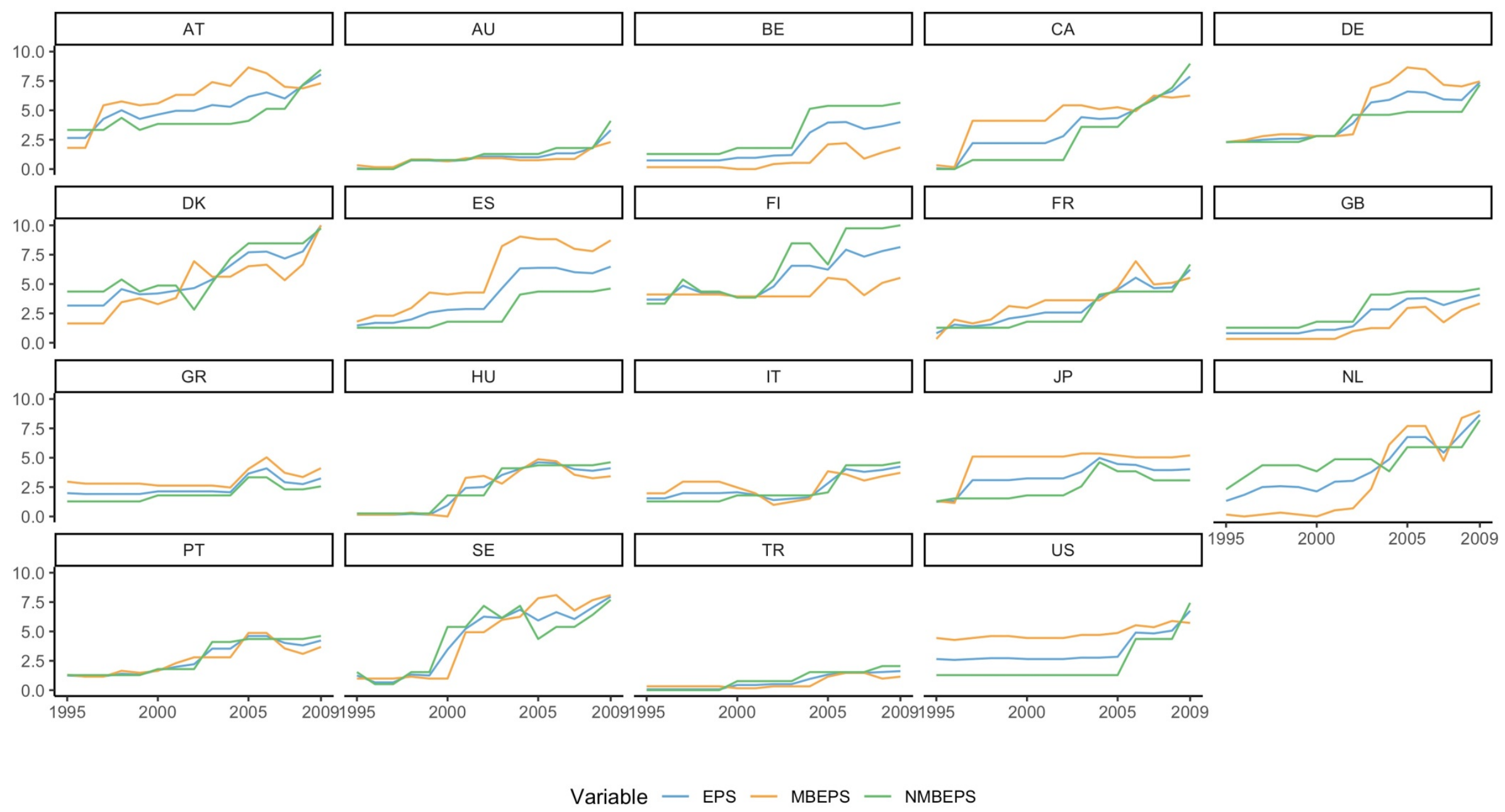

Fig. 2. Composite indexes: EPS, MBEPS and NMBEPS, 1995-2009. 


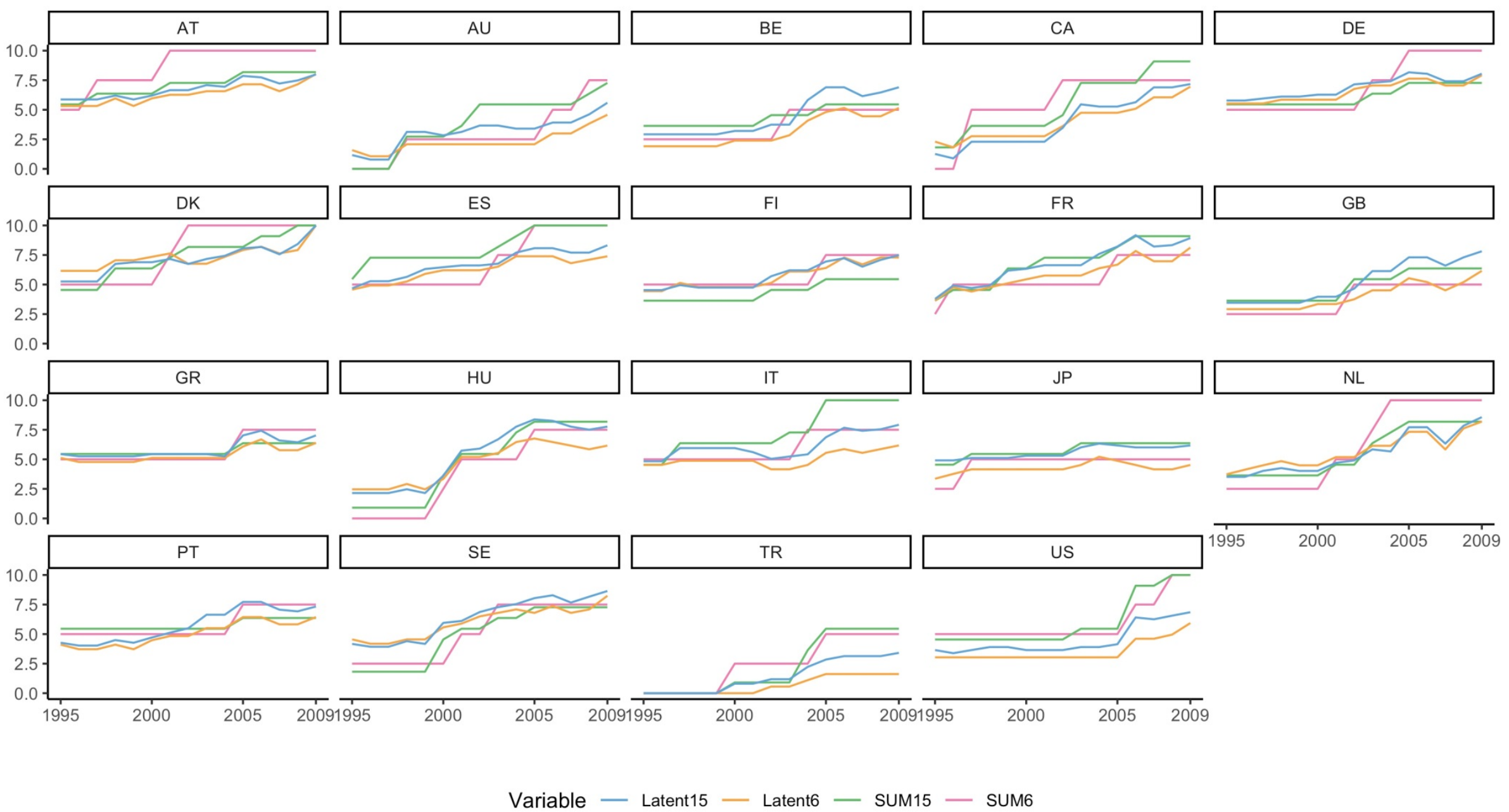

Fig. 3. Composite indexes: SUM6, SUM15, LATENT6, LATENT15, 1995-2009. 


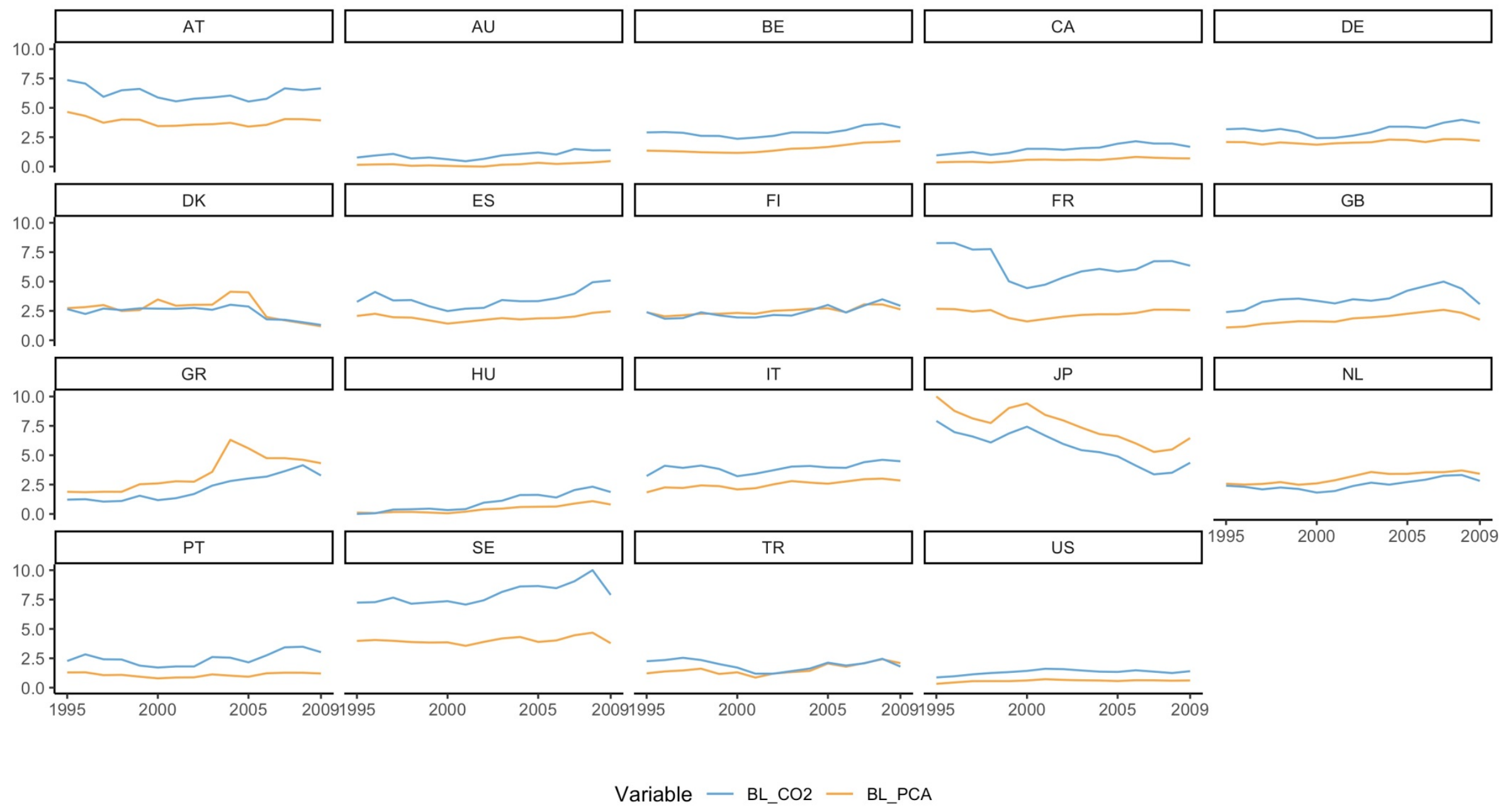

Fig. 3. Emission-based indicators: BL_CO2 and BL_PCA, 1995-2009. 

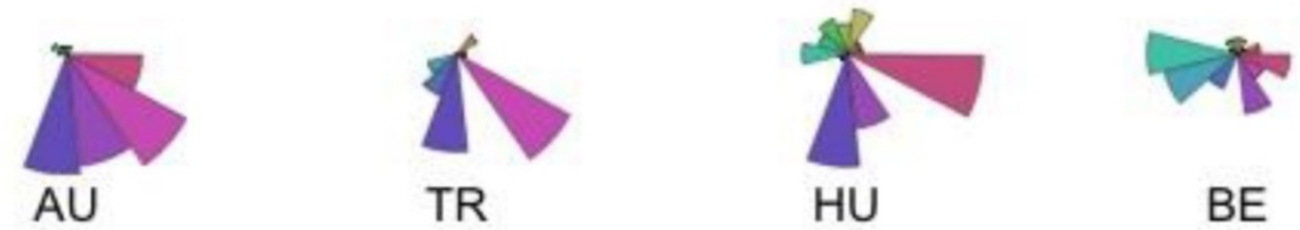

HU

BE

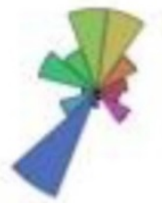

GR

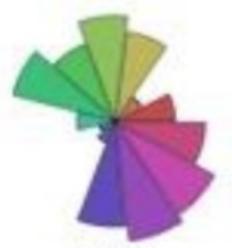

US

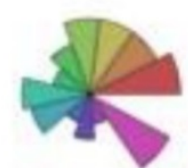

PT

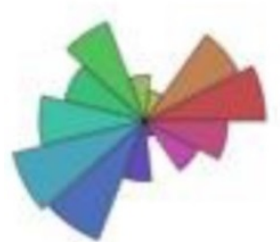

SE

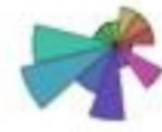

GB
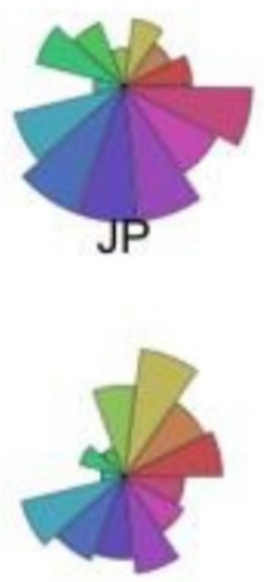

IT

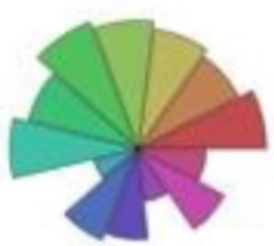

DK
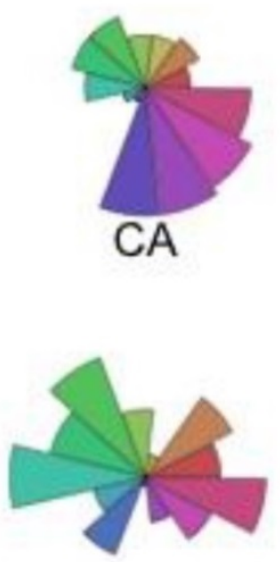

FI

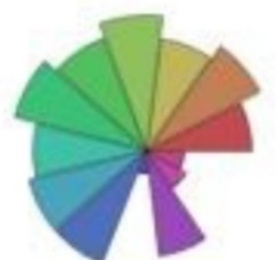

AT

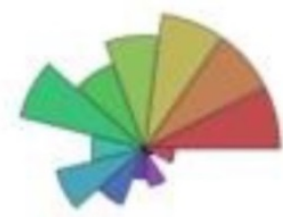

ES

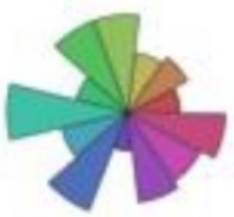

NL

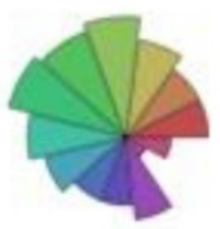

DE

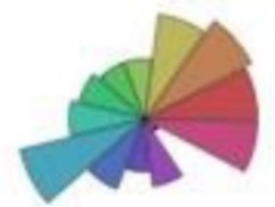

FR

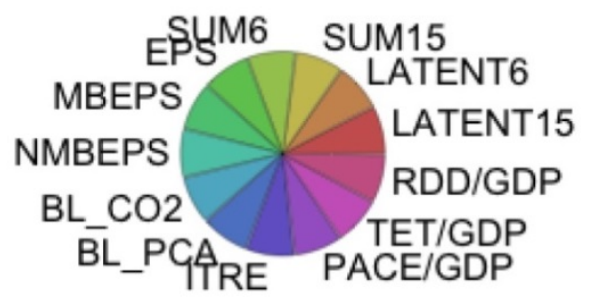

Fig. 4. Rankings of policy indicators, by country. 
Height

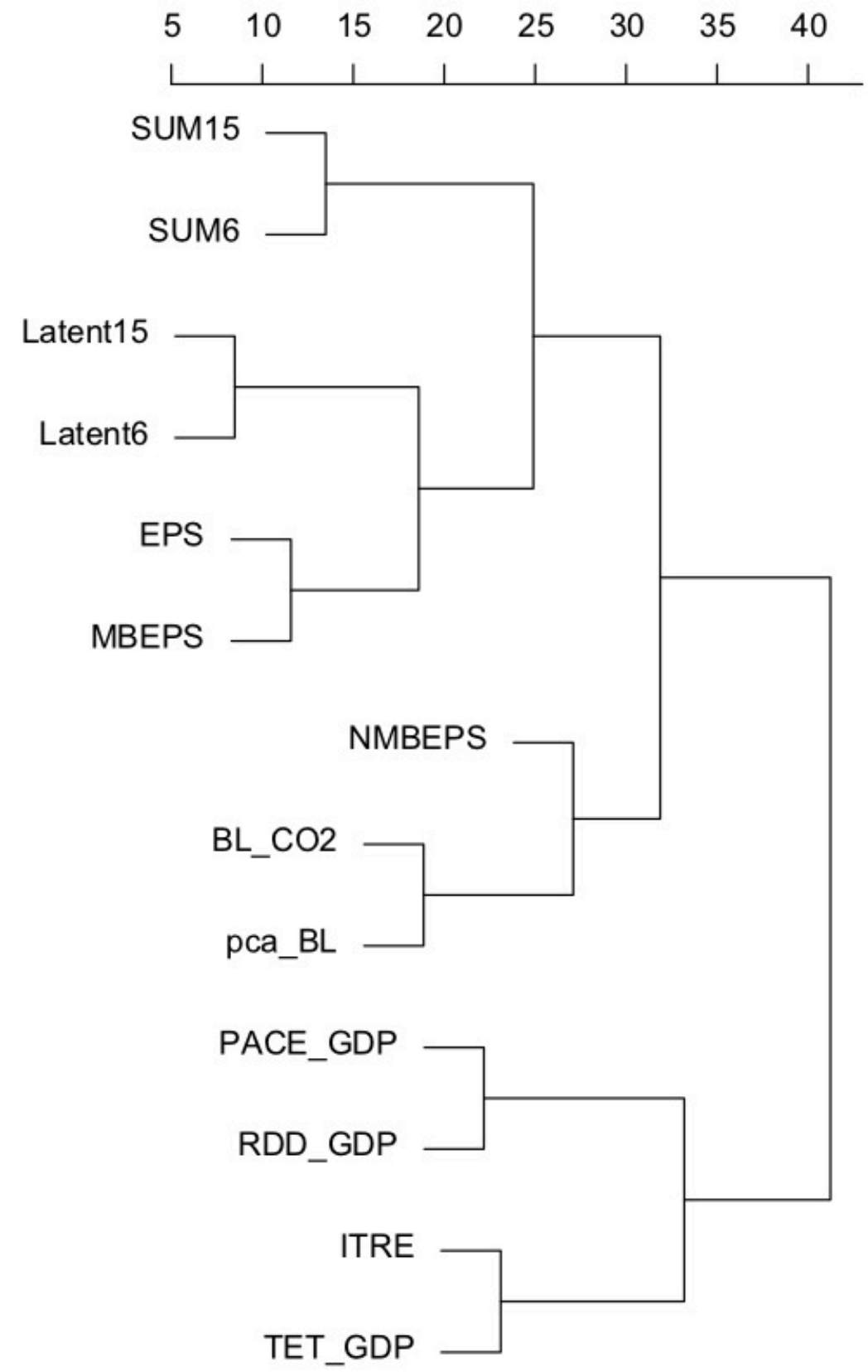

Fig. 5. Dendogram for different indicators. 


\section{Table 1}

List of countries and environmental policy indicators and abbreviations.

\begin{tabular}{|c|c|c|c|c|}
\hline Country & Abbreviation & & Environmental policy indicator & Abbreviation \\
\hline Australia & $\mathrm{AU}$ & $\mathrm{I}_{1}$ & Pollution abatement and control expenditures over GDP & PACE/GDP \\
\hline Austria & AT & $\mathrm{I}_{2}$ & Government R\&D expenditures over GDP & $\mathrm{R} \& \mathrm{D} / \mathrm{GDP}$ \\
\hline Belgium & $\mathrm{BE}$ & $\mathrm{I}_{3}$ & Implicit tax rate on energy & ITRE \\
\hline Canada & CA & $\mathrm{I}_{4}$ & Total revenue for energy and environmental taxes over GDP & TET/GDP \\
\hline Denmark & DK & $\mathrm{I}_{5}$ & OECD environmental policy stringency indicator (all instruments) & EPS \\
\hline Finland & FI & $\mathrm{I}_{6}$ & OECD environmental policy stringency indicator (market-based instruments) & MBEPS \\
\hline France & FR & $\mathrm{I}_{7}$ & OECD environmental policy stringency indicator (non market-based instruments) & NMBEPS \\
\hline Germany & $\mathrm{DE}$ & $\mathrm{I}_{8}$ & Sum of dummy indicators (fifteen individual instruments) & SUM15 \\
\hline Greece & GR & $\mathrm{I}_{9}$ & Sum of dummy indicators (six categorical aggregate instruments ) & SUM6 \\
\hline Hungary & HU & $\mathrm{I}_{10}$ & Three-level random intercept model-based indicator (fifteen individual instruments) & LATENT15 \\
\hline Italy & IT & $\mathrm{I}_{11}$ & Three-level random intercept model-based indicator (six categorical aggregate instruments) & LATENT6 \\
\hline Japan & $\mathrm{JP}$ & $\mathrm{I}_{12}$ & Brunel and Levinson emission-based indicator ( $\mathrm{CO} 2$ emissions) & BL_CO2 \\
\hline Netherlands & NL & $\mathrm{I}_{13}$ & Brunel and Levinson indicator (principal components of various emission-based indicators) & BL_PCA \\
\hline Portugal & PT & & & \\
\hline Spain & ES & & & \\
\hline Sweden & SE & & & \\
\hline Turkey & TR & & & \\
\hline United Kingdom & GB & & & \\
\hline United States of A. & US & & & \\
\hline
\end{tabular}




\section{Table 2}

Descriptive statistics for all indicators, country averages 1995-2009.

\begin{tabular}{|c|c|c|c|c|c|c|c|c|c|c|c|c|c|}
\hline & PACE/GDP & $\mathrm{R} \& \mathrm{D} / \mathrm{GDP}$ & ITRE & TET/GDP & EPS & MBEPS & NMBEPS & SUM6 & SUM15 & LATENT6 & LATENT15 & $\mathrm{BL} \_\mathrm{CO} 2$ & BL_PCA \\
\hline Australia & & 1.49 & & & 0.99 & 0.89 & 1.13 & 2.92 & 3.64 & 2.77 & 3.30 & 0.97 & 0.18 \\
\hline Austria & 7.99 & 0.95 & 1.63 & 4.72 & 4.96 & 5.39 & 4.44 & 8.06 & 6.77 & 6.40 & 6.66 & 6.25 & 3.83 \\
\hline Belgium & 4.11 & 1.35 & 0.34 & 4.48 & 1.97 & 0.73 & 2.93 & 3.61 & 4.39 & 3.54 & 4.64 & 2.91 & 1.53 \\
\hline Canada & & 2.20 & & & 3.29 & 3.99 & 2.67 & 5.14 & 5.30 & 4.27 & 4.04 & 1.52 & 0.57 \\
\hline Denmark & 4.09 & 1.47 & 8.05 & 8.96 & 5.60 & 4.72 & 6.06 & 7.64 & 7.22 & 7.53 & 7.14 & 2.39 & 2.71 \\
\hline Finland & 3.38 & 3.68 & 0.40 & 5.81 & 5.49 & 4.37 & 6.14 & 5.83 & 4.39 & 5.91 & 5.82 & 2.40 & 2.48 \\
\hline France & 4.16 & 2.43 & 2.56 & 3.97 & 2.99 & 3.27 & 2.71 & 5.42 & 6.67 & 5.95 & 6.57 & 6.35 & 2.29 \\
\hline Germany & 4.71 & 0.96 & 3.21 & 4.45 & 4.31 & 4.77 & 3.82 & 6.94 & 6.16 & 6.72 & 6.86 & 3.17 & 2.10 \\
\hline Greece & 1.18 & 0.47 & 1.17 & 4.57 & 2.53 & 3.18 & 2.00 & 5.94 & 5.80 & 5.70 & 6.04 & 2.19 & 3.47 \\
\hline Hungary & 4.67 & 4.38 & & 0.87 & 2.47 & 2.35 & 2.53 & 4.22 & 5.06 & 5.08 & 5.63 & 1.00 & 0.43 \\
\hline Italy & 6.17 & 1.43 & 6.19 & 5.58 & 2.42 & 2.56 & 2.29 & 5.97 & 7.27 & 5.33 & 6.20 & 3.94 & 2.50 \\
\hline Japan & & 4.35 & & & 3.18 & 4.25 & 2.29 & 4.58 & 5.71 & 4.50 & 5.61 & 5.70 & 7.56 \\
\hline Netherlands & 5.61 & 2.10 & 2.44 & 6.73 & 4.15 & 3.12 & 4.81 & 5.97 & 5.61 & 5.91 & 5.58 & 2.50 & 3.08 \\
\hline Portugal & 2.67 & 0.11 & 2.49 & 6.84 & 2.61 & 2.49 & 2.67 & 5.83 & 5.76 & 5.24 & 5.77 & 2.48 & 1.09 \\
\hline Spain & 3.24 & 0.64 & 1.90 & 3.41 & 3.77 & 5.23 & 2.54 & 6.81 & 7.93 & 6.29 & 6.57 & 3.51 & 1.92 \\
\hline Sweden & 2.07 & 1.57 & 2.99 & 5.47 & 4.26 & 4.20 & 4.17 & 5.00 & 4.70 & 6.18 & 6.30 & 7.95 & 4.03 \\
\hline Turkey & 1.01 & 0.13 & & & 0.62 & 0.55 & 0.76 & 2.21 & 2.03 & 1.06 & 1.57 & 1.93 & 1.56 \\
\hline United Kingdom & 2.51 & 0.41 & 3.32 & 4.77 & 2.20 & 1.51 & 2.72 & 3.89 & 4.95 & 4.44 & 5.38 & 3.56 & 1.81 \\
\hline USA & & 1.75 & & & 3.42 & 4.68 & 2.36 & 6.11 & 6.01 & 3.91 & 4.56 & 1.32 & 0.58 \\
\hline
\end{tabular}

Note: Indicator averages are not reported for those countries in which there are missing values. 


\section{Table 3}

Spearman correlation matrix among alternative indicators.

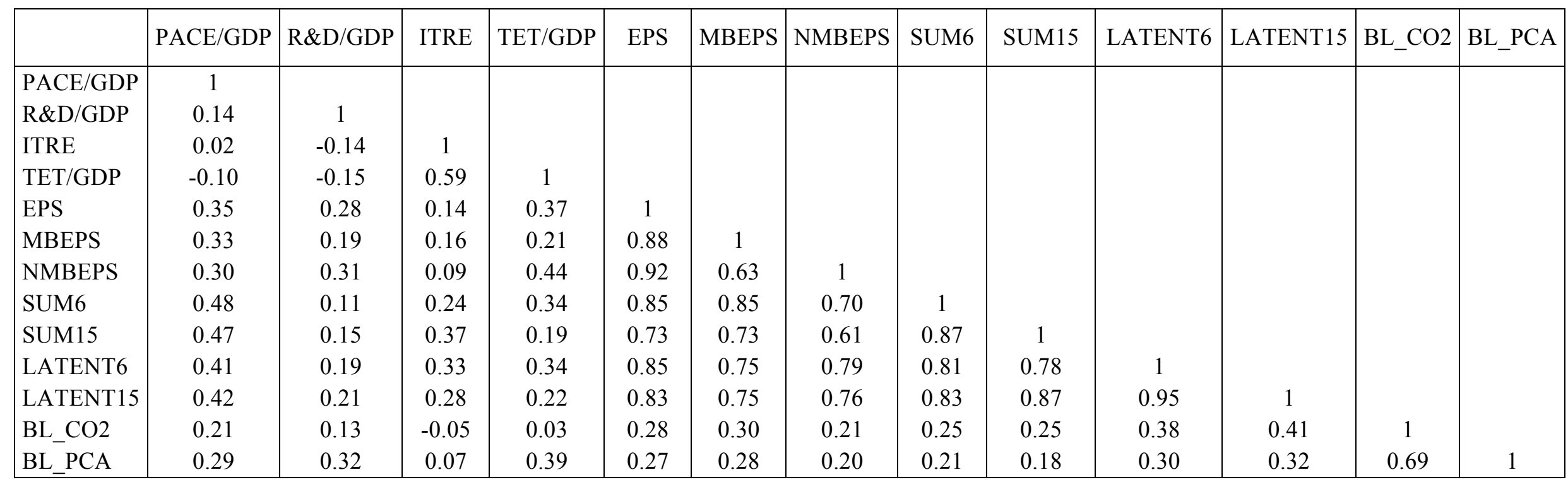




\section{Table 4}

Rankings associated with alternative indicators.

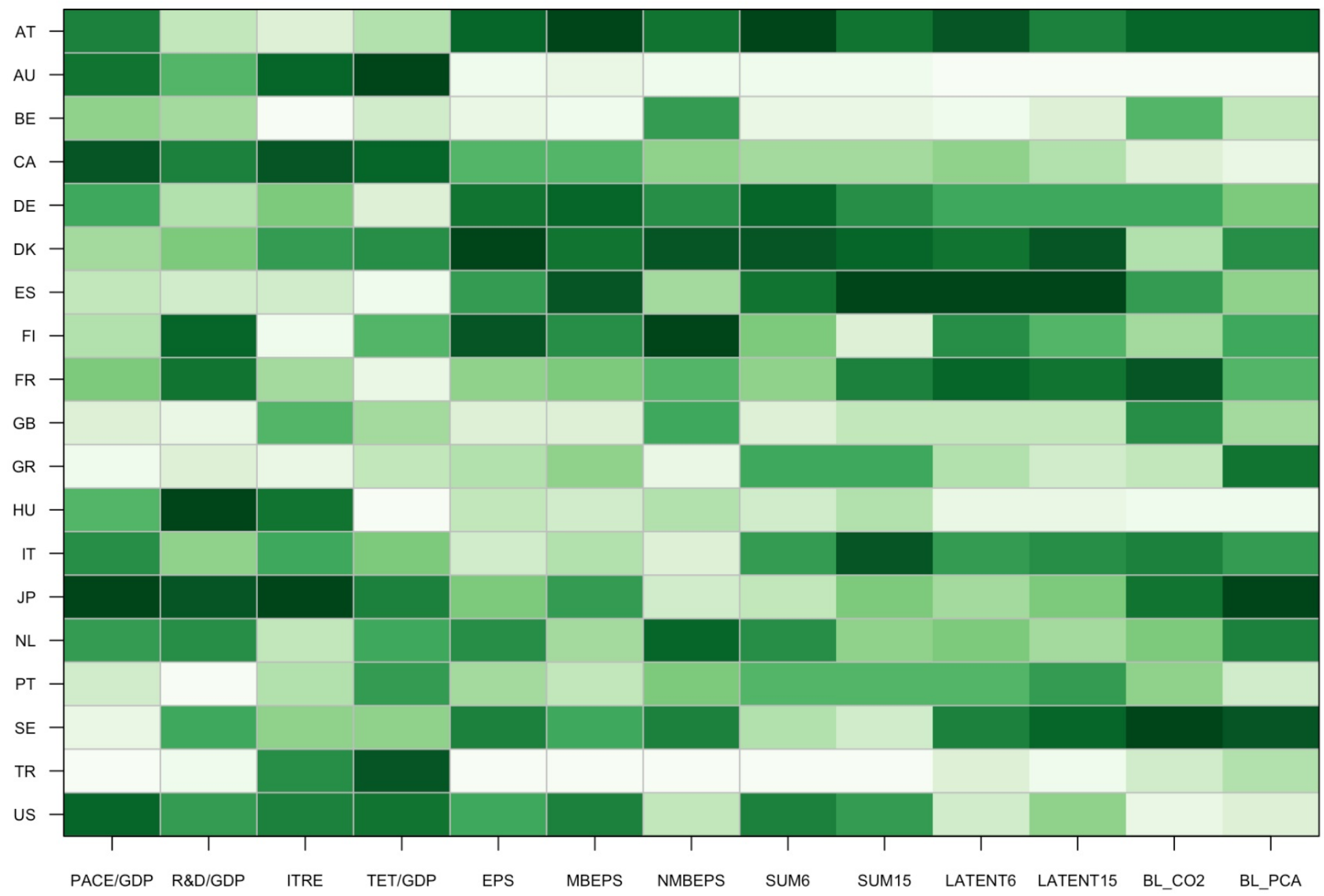

Notes: The rankings range from lowest level of environmental policy stringency for a give indicator (white color) to highest level of environmental policy stringency for a give indicator (dark green color). 


\section{Table 5}

Patent regressions - Panel A.

\begin{tabular}{|c|c|c|c|c|c|c|c|c|c|c|c|c|c|}
\hline \multirow{2}{*}{$\begin{array}{c}\text { Dep. Var. } \\
\text { InPATR } \\
\text { Explanatory } \\
\text { Variables }\end{array}$} & \multirow[t]{2}{*}{$\begin{array}{c}\mathrm{NO} \\
\text { INDICATOR }\end{array}$} & \multicolumn{2}{|c|}{ PACE/GDP } & \multicolumn{2}{|c|}{ RDD/GDP } & \multicolumn{2}{|c|}{ TET/GDP } & \multicolumn{2}{|c|}{ ITRE } & \multicolumn{2}{|c|}{ SUM6 } & \multicolumn{2}{|c|}{ SUM15 } \\
\hline & & current & lagged & current & lagged & current & lagged & current & lagged & current & lagged & current & lagged \\
\hline \multirow[t]{2}{*}{$\ln G D P$} & 2.026 & 2.449 & 2.131 & 2.296 & 2.310 & 1.262 & 1.468 & 1.776 & 1.959 & 1.946 & 2.167 & 1.940 & 2.257 \\
\hline & 3.830 & 3.583 & 3.057 & 3.951 & 3.733 & 2.266 & 2.531 & 3.166 & 3.254 & 3.674 & 4.012 & 3.714 & 4.240 \\
\hline \multirow[t]{2}{*}{$\ln K P A T R$} & 1.718 & 1.862 & 1.849 & 1.713 & 1.708 & 1.653 & 1.593 & 1.703 & 1.604 & 1.725 & 1.715 & 1.704 & 1.719 \\
\hline & 10.325 & 9.423 & 8.663 & 9.948 & 9.963 & 6.416 & 6.319 & 6.324 & 5.927 & 10.512 & 10.268 & 10.476 & 10.305 \\
\hline \multirow[t]{2}{*}{$P E$} & 0.008 & 0.009 & 0.004 & 0.011 & 0.008 & 0.010 & 0.005 & 0.012 & 0.008 & 0.007 & 0.005 & 0.008 & 0.006 \\
\hline & 2.134 & 1.645 & 0.840 & 2.647 & 2.784 & 1.668 & 1.163 & 2.071 & 1.900 & 1.975 & 1.735 & 2.035 & 1.845 \\
\hline \multirow[t]{2}{*}{$I_{(n)}$} & & -0.022 & -0.020 & -0.021 & -0.033 & 0.053 & 0.013 & 0.026 & -0.007 & 0.024 & 0.013 & 0.014 & -0.004 \\
\hline & & -1.288 & -1.087 & -1.105 & -1.537 & 1.369 & 0.417 & 0.884 & -0.315 & 2.170 & 1.187 & 0.986 & -0.326 \\
\hline Adjusted $\mathrm{R}^{2}$ & 0.784 & 0.792 & 0.790 & 0.809 & 0.839 & 0.781 & 0.817 & 0.808 & 0.843 & 0.787 & 0.809 & 0.784 & 0.808 \\
\hline $\log L$ & 71.540 & 51.139 & 52.534 & 84.372 & 103.955 & 61.201 & 80.598 & 70.432 & 90.247 & 74.273 & 87.815 & 72.216 & 86.976 \\
\hline F test & 31.213 & 21.318 & 20.327 & 32.526 & 38.296 & 21.290 & 25.324 & 22.999 & 28.044 & 30.939 & 34.091 & 30.423 & 33.849 \\
\hline No obs. & 301 & 199 & 186 & 277 & 258 & 211 & 197 & 195 & 182 & 301 & 282 & 301 & 282 \\
\hline
\end{tabular}

Note: t-ratios in italics. 


\section{Table 5}

Patent regressions - Panel B.

\begin{tabular}{|c|c|c|c|c|c|c|c|c|c|c|c|c|c|c|}
\hline Dep. Var. $\ln P A T R$ & \multicolumn{2}{|c|}{ EPS } & \multicolumn{2}{|c|}{ MBEPS } & \multicolumn{2}{|c|}{ NMBEPS } & \multicolumn{2}{|c|}{ LATENT6t } & \multicolumn{2}{|c|}{ LATENT15t } & \multicolumn{2}{|c|}{ BL_PCA } & \multicolumn{2}{|c|}{$\mathrm{BL} \_\mathrm{CO} 2$} \\
\hline $\begin{array}{l}\text { Explanatory } \\
\text { Variables }\end{array}$ & current & lagged & current & lagged & current & lagged & current & lagged & current & lagged & current & lagged & current & lagged \\
\hline \multirow[t]{2}{*}{$\ln G D P$} & 2.005 & 2.215 & 2.065 & 2.231 & 1.982 & 2.232 & 1.880 & 2.258 & 1.942 & 2.313 & 1.751 & 1.794 & 1.792 & 2.002 \\
\hline & 3.767 & 4.126 & 3.910 & 4.178 & 3.682 & 4.149 & 3.555 & 4.191 & 3.582 & 4.253 & 3.125 & 3.354 & 3.131 & 3.526 \\
\hline \multirow[t]{2}{*}{$\ln K P A T R$} & 1.706 & 1.710 & 1.714 & 1.709 & 1.710 & 1.715 & 1.714 & 1.715 & 1.710 & 1.722 & 1.818 & 1.789 & 1.760 & 1.723 \\
\hline & 10.476 & 10.168 & 10.542 & 10.265 & 10.278 & 10.154 & 10.505 & 10.213 & 10.341 & 10.295 & 10.628 & 10.490 & 10.111 & 10.184 \\
\hline \multirow[t]{2}{*}{$P E$} & 0.008 & 0.005 & 0.008 & 0.005 & 0.008 & 0.006 & 0.008 & 0.006 & 0.008 & 0.006 & 0.008 & 0.005 & 0.008 & 0.005 \\
\hline & 1.964 & 1.763 & 2.129 & 1.763 & 1.974 & 1.827 & 2.009 & 1.856 & 2.013 & 1.972 & 1.935 & 1.452 & 1.847 & 1.475 \\
\hline \multirow[t]{2}{*}{$I_{(n)}$} & 0.042 & 0.010 & 0.025 & 0.011 & 0.022 & -0.002 & 0.047 & -0.009 & 0.018 & -0.017 & 0.056 & 0.083 & 0.030 & 0.032 \\
\hline & 3.092 & 0.706 & 2.978 & 1.243 & 1.919 & -0.173 & 1.949 & -0.352 & 0.876 & -0.848 & 1.344 & 3.222 & 1.553 & 1.859 \\
\hline Adjusted $\mathrm{R}^{2}$ & 0.789 & 0.808 & 0.788 & 0.809 & 0.785 & 0.808 & 0.786 & 0.808 & 0.784 & 0.809 & 0.764 & 0.818 & 0.761 & 0.810 \\
\hline $\log L$ & 76.013 & 87.140 & 75.245 & 87.587 & 73.046 & 86.918 & 73.710 & 86.975 & 72.031 & 87.361 & 65.510 & 94.309 & 63.992 & 88.237 \\
\hline F test & 31.382 & 33.896 & 31.186 & 34.025 & 30.631 & 33.832 & 30.797 & 33.848 & 30.377 & 33.960 & 25.620 & 36.019 & 25.276 & 34.214 \\
\hline No obs. & 301 & 282 & 301 & 282 & 301 & 282 & 301 & 282 & 301 & 282 & 283 & 282 & 283 & 282 \\
\hline
\end{tabular}

Note: t-ratios in italics. 


\section{Table 6}

Energy-GDP regressions - Panel A.

\begin{tabular}{|c|c|c|c|c|c|c|c|c|c|c|c|c|c|}
\hline \multirow{2}{*}{$\begin{array}{c}\text { Dep. Var. } \ln E I \\
\text { Explanatory } \\
\text { Variables }\end{array}$} & \multirow{2}{*}{$\begin{array}{c}\text { NO } \\
\text { INDICATOR }\end{array}$} & \multicolumn{2}{|c|}{ PACE/GDP } & \multicolumn{2}{|c|}{ RDD/GDP } & \multicolumn{2}{|c|}{ TET/GDP } & \multicolumn{2}{|c|}{ ITRE } & \multicolumn{2}{|c|}{ SUM6 } & \multicolumn{2}{|c|}{ SUM15 } \\
\hline & & current & lagged & current & lagged & current & lagged & current & lagged & current & lagged & current & lagged \\
\hline \multirow[t]{2}{*}{$\ln (G D P / P)$} & 1.193 & 1.574 & 1.734 & 1.783 & 1.786 & 0.355 & 0.344 & 1.977 & 2.628 & 1.201 & 1.290 & 1.394 & 1.465 \\
\hline & -4.600 & 4.798 & 5.942 & 6.402 & 7.625 & 0.765 & 0.719 & 1.406 & 1.405 & 4.563 & 4.686 & 5.520 & 5.453 \\
\hline \multirow[t]{2}{*}{$\ln ^{2}(G D P / P)$} & -0.289 & -0.356 & -0.379 & -0.372 & -0.375 & -0.174 & -0.170 & -0.397 & -0.492 & -0.289 & -0.303 & -0.316 & -0.328 \\
\hline & -6.729 & -6.005 & -6.800 & -7.953 & -8.955 & -2.221 & -2.084 & -1.878 & -1.771 & -6.640 & -6.587 & -7.546 & -7.275 \\
\hline \multirow[t]{2}{*}{$I_{(n)}$} & & -0.0013 & -0.0035 & -0.0029 & -0.0035 & 0.0215 & 0.0286 & -0.0246 & -0.0170 & -0.0045 & -0.0023 & -0.0124 & -0.0090 \\
\hline & & -0.302 & -0.880 & -1.434 & -1.447 & 2.331 & 3.192 & -6.415 & -4.516 & -2.231 & -1.182 & -5.096 & -3.863 \\
\hline Adjusted $\mathrm{R}^{2}$ & 0.975 & 0.969 & 0.971 & 0.976 & 0.978 & 0.965 & 0.969 & 0.971 & 0.970 & 0.975 & 0.977 & 0.977 & 0.978 \\
\hline $\log L$ & 563.455 & 373.746 & 364.692 & 521.884 & 505.286 & 380.413 & 371.052 & 370.807 & 347.015 & 564.023 & 546.514 & 575.596 & 553.436 \\
\hline $\mathrm{F}$ test & 336.833 & 172.363 & 177.450 & 314.602 & 324.053 & 164.377 & 172.004 & 185.406 & 166.516 & 330.852 & 335.894 & 357.702 & 352.955 \\
\hline No obs. & 304 & 201 & 189 & 279 & 261 & 213 & 199 & 197 & 184 & 303 & 285 & 303 & 285 \\
\hline
\end{tabular}

Note: t-ratios in italics. 


\section{Table 6}

Energy-GDP regressions - Panel B.

\begin{tabular}{|c|c|c|c|c|c|c|c|c|c|c|c|c|c|c|}
\hline Dep. Var. $\ln E I$ & \multicolumn{2}{|c|}{ EPS } & \multicolumn{2}{|c|}{ MBEPS } & \multicolumn{2}{|c|}{ NMBEPS } & \multicolumn{2}{|c|}{ LATENT6 } & \multicolumn{2}{|c|}{ LATENT15 } & \multicolumn{2}{|c|}{$\mathrm{BL} \_\mathrm{CO} 2$} & \multicolumn{2}{|c|}{ BL_PCA } \\
\hline $\begin{array}{l}\text { Explanatory } \\
\text { Variables }\end{array}$ & current & lagged & current & lagged & current & lagged & current & lagged & current & lagged & current & lagged & current & lagged \\
\hline \multirow[t]{2}{*}{$\ln (G D P / P)$} & 1.095 & 1.198 & 1.141 & 1.268 & 1.091 & 1.183 & 1.172 & 1.292 & 1.319 & 1.430 & 1.198 & 1.248 & 1.193 & 1.265 \\
\hline & 4.104 & 4.426 & 4.221 & 4.561 & 4.102 & 4.422 & 4.520 & 4.923 & 5.301 & 5.693 & 4.577 & 4.660 & 4.316 & 4.507 \\
\hline \multirow[t]{2}{*}{$\ln ^{2}(G D P / P)$} & -0.273 & -0.289 & -0.281 & -0.301 & -0.271 & -0.285 & -0.281 & -0.300 & -0.301 & -0.319 & -0.279 & -0.287 & -0.292 & -0.301 \\
\hline & -6.271 & -6.424 & -6.396 & -6.543 & -6.176 & -6.318 & -6.514 & -6.727 & -7.241 & -7.463 & -6.274 & -6.260 & -6.442 & -6.459 \\
\hline \multirow{2}{*}{$I_{(n)}$} & -0.0044 & -0.0055 & -0.0007 & 0.0002 & -0.0050 & -0.0074 & -0.0066 & -0.0064 & -0.0123 & -0.0110 & -0.0096 & -0.0084 & 0.0003 & 0.0004 \\
\hline & -1.215 & -1.662 & -0.281 & 0.073 & -1.750 & -2.975 & -2.205 & -2.433 & -4.556 & -4.295 & -2.012 & -1.997 & 0.065 & 0.098 \\
\hline Adjusted $\mathrm{R}^{2}$ & 0.975 & 0.977 & 0.975 & 0.977 & 0.975 & 0.978 & 0.975 & 0.977 & 0.977 & 0.978 & 0.976 & 0.977 & 0.976 & 0.977 \\
\hline $\log \mathrm{L}$ & 562.678 & 547.701 & 561.525 & 545.793 & 563.445 & 550.398 & 564.577 & 548.760 & 573.485 & 555.689 & 536.451 & 548.279 & 533.613 & 545.792 \\
\hline $\mathrm{F}$ test & 327.863 & 338.760 & 325.320 & 334.163 & 329.564 & 345.365 & 332.092 & 341.340 & 352.650 & 358.691 & 322.436 & 340.167 & 315.943 & 334.162 \\
\hline No obs. & 303 & 285 & 303 & 285 & 303 & 285 & 303 & 285 & 303 & 285 & 285 & 285 & 285 & 285 \\
\hline
\end{tabular}

Note: t-ratios in italics. 